\title{
Topraksız kültür üzüm yetiştiriciliğinde farklı besin çözeltilerinin ve yetiştirme ortamlarının verim ve kaliteye etkisi
}

\section{Effects of different nutrient solutions and growing media on yield and quality in grape growing in soilless culture \\ Serpil TANGOLAR ${ }^{1 \oplus}$, SemihTANGOLAR ${ }^{1}$, Ayfer ALKAN TORUN ${ }^{2} \oplus$, Güzin TARIM ${ }^{3}{ }^{\oplus}$, Melike ADA ${ }^{1}$, Oğuzhan AYDIN²}

${ }^{1}$ Çukurova Üniversitesi, Ziraat Fakültesi, Bahçe Bitkileri Bölümü, Adana

${ }^{2}$ Çukurova Üniversitesi, Ziraat Fakültesi, Toprak Bilimi ve Bitki Besleme Bölümü, Adana

${ }^{3}$ Alata Bahçe Kültürleri Araştırma Enstitüsü, Erdemli, Mersin

Sorumlu yazar (Corresponding author): S. Tangolar, e-posta (e-mail): stangolar@cu.edu.tr

Yazar(lar) e-posta (Author e-mail): tangolar@cu.edu.tr, atorun@cu.edu.tr, caymazguzin@gmail.com, melikeada46@gmail.com, oguzhanaydiin@gmail.com

\section{MAKALE BİLGISİ}

Alınıs tarihi 12 Mart 2019

Düzeltilme tarihi 19 Nisan 2019

Kabul tarihi 26 Nisan 2019

\section{Anahtar Kelimeler:}

Asma

Besin çözeltisi

Mineral element

Topraksız kültür

Klorofil

\begin{abstract}
ÖZ
Bu calısma, Early Sweet ve Trakya İlkeren üzüm cesitlerinde, 3 farklı katı yetistirme Perlit:Torf (2:1), Kokopit ve Pomza (Bazaltik Pomza), 2 farklı değiştirilmiş Hoagland besin çözeltisinin (A ve B) bitkilerin vejetatif büyümeleri yanında yaprakların besin elementi ve klorofil düzeyleri ile verim ve kalite özellikleri üzerine etkisini belirlemek amacıyla yürütülmüştür. İki çeşitte de farklı fenolojik zamanlarda ölçülen gövde capları üzerine farklı ortam ve besin çözeltisi uygulamasının önemli bir etkisinin olmadığı belirlenmiş̦tir. Üzümlerin olgunluk zamanında ölçülen SPAD değerleri bakımından yetistirme ortamları arasındaki farkl11ı̆ıın önemli; besin çözeltileri arasındaki farkl1ıı̆ın ise önemsiz olduğu görülmüștür. En yüksek SPAD değerleri, Early Sweet' de ayn istatistiksel grupta yer alan Pomza (47.37) ve Perlit:Torf (46.32) ortamlarında; Trakya İlkeren çeșidinde ise Pomza (43.62) ortamındaki bitkilerde ölçülmüstür. En yüksek verim ve salkım ağırlkları Early Sweet ceșidinde Pomza (sırasıyla $2066 \mathrm{~g}$ omca $^{-1}$ ve $344.4 \mathrm{~g}$ ); Trakya İlkeren'de Perlit:Torf (sırasıyla $1981 \mathrm{~g}^{\text {omca }}{ }^{-1}$ ve $495.1 \mathrm{~g}$ ) ortamından elde edilmiştir. Her iki çeşitte de verim ve salkım ağırlığını $\mathrm{B}$ besin çözzeltisi uygulaması altında daha yüksek olduğu saptanmıştır. Trakya İlkeren çeşidi yaprak örneklerinde azot $(\mathrm{N})$, fosfor $(\mathrm{P})$, potasyum $(\mathrm{K})$ ve magnezyum $(\mathrm{Mg})$ konsantrasyonları ortam ve besin çözeltisine göre farkl1lık göstermiștir. Tüm uygulamalarda kalsiyum (Ca)'un noksan; çinko $(\mathrm{Zn})$, mangan $(\mathrm{Mn})$ ve bakır $(\mathrm{Cu})$ 'n yeterli, Early Sweet'de ise $\mathrm{N}, \mathrm{P}, \mathrm{Mg}$ ve demir (Fe)'in fazla; $\mathrm{K}$ ve Ca'un noksan, $\mathrm{Zn}$, Mn ve Cu'in yeterli olduğu değerlendirilmiş̧tir. Sonuç olarak topraksız üzüm yetiştiriciliği için uygun ortamın çeşitlere göre değişebileceği, B besin çözeltisi (makro element miktarını yüksek, mikro element miktarını daha düșük düzeyde içeren) kullanılmasının verim ve kaliteyi arttırdığı belirlenmiștir.
\end{abstract}

\section{ARTICLE INFO}

Received 12 March 2019

Received in revised form 19 April 2019 Accepted 26 April 2019

\section{Keywords:}

Grapevine

Nutrient solution

Mineral element

Hydroponic culture

Chlorophyll

\begin{abstract}
This study was carried out in Early Sweet and Trakya Ilkeren grape varieties to determine the effects of 3 different solid growing medium Perlite: Peat (2: 1), Cocopeat and Pumice (Basaltic Pumice) and 2 different modified Hoagland nutrient solutions (A and B) on vegetative growth as well as the nutrient element content and chlorophyll levels of the leaves and grape yield and quality characteristics. It was determined that different media and nutrient solution application had no significant effect on stem diameters measured at different phenological stages in both varieties. In terms of SPAD values measured at the time of maturity of grapes, the difference between growing media was important but the difference between nutrient solutions was insignificant. The highest SPAD values were measured in Pumice (47.37) and Perlite:Peat (46.32) media in the same statistical group for Early Sweet and in the Pumice (43.62) for Trakya Ilkeren variety. The highest yield and cluster weight were obtained from Pumice $\left(2066 \mathrm{~g}^{-1} \mathrm{vin}^{-1}\right.$ and $344.4 \mathrm{~g}$, respectively) for Early Sweet variety; from Perlite:Peat (1981 g vine ${ }^{-1}$ and $495.1 \mathrm{~g}$ respectively) for Trakya Ilkeren. In both varieties, yield and cluster weight were higher in B nutrient solution application. Nitrogen $(\mathrm{N})$, phosphorus $(\mathrm{P})$, potassium $(\mathrm{K})$ and magnesium $(\mathrm{Mg})$ concentrations in Trakya Ilkeren leaf samples were different according to the media and nutrient solution. In all applications; calcium (Ca) insufficient; zinc $(\mathrm{Zn})$, manganese $(\mathrm{Mn})$ and copper $(\mathrm{Cu})$ were sufficient, while in Early Sweet $\mathrm{N}, \mathrm{P}, \mathrm{Mg}$ and iron $(\mathrm{Fe})$ excess; $\mathrm{K}$ and $\mathrm{Ca}$ insufficient; $\mathrm{Zn}, \mathrm{Mn}$ and $\mathrm{Cu}$ were found to be sufficient. As a result, it was determined that the suitable medium for table grape growing in soilless culture could vary according to the varieties, and that the use of B nutrient solution (containing a high amount of macro elements and a lower level of micro elements) increased yield and quality.
\end{abstract}




\section{Giriş}

Bağcılık, Akdeniz Bölgesinde bahçe bitkilerine ayrılan tarım alanları içerisinde en geniş alana ve üretim değerine sahiptir. Bölgenin önemli geçim ve besin kaynağından birisi bağcllıktır. Suyun ve besin maddelerinin verim ve kaliteyi geliştirecek bir program içinde kontrollü ve etkin şekilde kullanımını sağlayan topraksız kültür yetiştiricilik ile sofralık üzüm yetiştiriciliğinin geliştirilebileceği düşünülmektedir. $\mathrm{Bu}$ tekniğin, özellikle erkenci sofralık üzüm yetiştiricileri için önemli bir alternatif teknik kazandıracağ artırma adına önemli katkı yapacağı, aynı zamanda kısıtlı su ve besin kaynaklarının daha etkin kullanımını sağlayarak, kontrolsüz gübre kullanımını da engelleyebileceği beklenmektedir.

Topraksız kültür sisteminde üzüm yetiştiriciliği konusunda yürütülmüş sınırlı sayıda araştırmaların çoğunluğu, uygun yetiştirme ortamını belirleme (Polat ve ark. 2003; Tangolar ve ark. 2016 ve 2017; Baştaş ve Tangolar 2018; Kaya ve ark. 2018) üzerine yapılmış çalışmalardır. Çok az çalışma ise farklı bitki besleme çözeltileri konusundadır. Bunlarda daha çok besin solüsyonları üzerinde makro veya mikro elementlerde değişiklik yapılması etkilerinin araştırıldığı ve temel besin çözeltisi olarak Hoagland çözeltisinin kullanıldığı görülmektedir (Buttaro ve ark. 2012; Tangolar ve ark. 2016; Tangolar ve ark. 2017).

Topraksız kültürde, bilgimiz dahilinde Di Lorenzo ve ark. (Di Lorenzo ve Mafrica 2000; Di Lorenzo ve ark. 2009 ve 2012) ile Buttaro ve ark. (2012) tarafindan İtalya'da, ülkemizde de Polat ve ark. (2003), Sabır ve ark. (2012 ve 2017), Tangolar ve ark. (2016 ve 2017) ve Baştaş ve Tangolar (2018) ile Kaya ve ark. (2018) tarafindan yapılmış çalışma dışında çok çalışma bulunmamaktadır. Bu çalışmalarda topraksız kültürün bağcılıkta uygulanabilirliği, yetiştirme ortamı, ürün yükü ve kök budaması uygulamalarının etkisinin belirlenmesi konusu incelenmiştir.

Topraksız kültür üzüm yetiştiriciliğinde en önemli konulardan birisi bitkilere gerekli besinlerin yeterli miktarda verilmesidir. Üzüm yetiştiriciliğinde kullanılacak optimum besin solüsyonu formülasyonunun belirlenmesinde; üzüm çeşidi, bitkinin gelişme evresi, sıcaklık, 1şık yoğunluğu, güneşlenme gibi ekolojik koşullar etkili olmaktadır (Di Lorenzo ve ark. 2005; Baştaş ve Tangolar 2018). Topraksız kültür üzüm yetiştiriciliğinde Cardinal, Victoria, Black Magic çeşitlerinde gübreleme konusu Buttaro ve ark. (2012) tarafindan çalışılmıştır. Çalışmada 4 farklı besin solüsyonu bileşimi kullanılmıştır. Bunlardan birincisi \%100 Hoagland'ın makro elementlerinde değişiklik yapmadan, ikincisi $\mathrm{N}, \mathrm{P}, \mathrm{K}, \mathrm{Ca}$ ve $\mathrm{Mg}$ da \%30 azaltma, üçüncüsü $\mathrm{N}$ ve $\mathrm{P}$ ' de $\% 30$ azaltma, dördüncüsü $\mathrm{N}, \mathrm{P}, \mathrm{Ca}$ ve $\mathrm{Mg}$ 'da \%30 azaltma yapılan besin çözeltileridir. Sonuçta en yüksek üzüm verimi $29.4 \mathrm{t} \mathrm{ha}^{-1}$ olarak elde edilmiştir. Tangolar ve ark. (2017)'da, Hoagland besin çözeltisini (Hoagland ve Arnon 1950) asmaya uyarlayarak Yalova İncisi çeşitlerinde kullandıkları çalışmalarında en yüksek verimi $57.2 \mathrm{tha}^{-1}$ olarak tespit etmişlerdir. $\mathrm{Bu}$ iki araştırmada kullanılan yetiştirme ortamının etkisinde, gübreleme ve çeşit açısından farklılıklar olduğu belirlenmiştir. Topraksız kültür üzüm yetiştiriciliğinde, genellikle çeşitlere özgü formülasyon saptamaya yönelik çalışmaların yapılması gerektiği öneriler arasında yer almaktadır.

$\mathrm{Bu}$ çalışma; Buttaro ve ark. (2012) ile Tangolar ve ark. (2017)'nın üzümde kullandıkları besin çözeltileri, farklı yetiştirme ortamlarında ve erkenci iki üzüm çeşidinde karşılaştırmalı olarak kullanılarak en uygun yetiştirme ortamı ve en uygun besin çözeltisinin, verim ve kalite ile bitkilerin besin elementi alımı üzerine etkilerini belirlemek amacıyla planlanmıştır.

\section{Materyal ve Yöntem}

Bu araştırma, Çukurova Üniversitesi Ziraat Fakültesi Bahçe Bitkileri Bölümü Araştırma ve Uygulama bağında topraksız kültür ortamında, taban genişliği $6.0 \mathrm{~m}$, uzunluğu $20 \mathrm{~m}$, yüksekliği $3.0 \mathrm{~m}$ olan ve $0.400 \mathrm{~mm}$ kalınlığında UV katkılı plastik ile örtülü bir serada yürütülmüştür. Çalışmada bitkisel materyal olarak Early Sweet ve Trakya İlkeren üzüm çeşitleri kullanılmıştır. Araştırmada 3 farklı katı (Perlit:Torf (2:1), Kokopit, Bazaltik Pomza) yetiştirme ortamında, 2 besin çözeltisinin (Tangolar ve ark. 2017 (A) ve Buttaro ve ark. 2012 (B) etkisi denenmiştir.

\subsection{Yetişstirme Ortamı Materyalleri}

Çalışmada etkisi denenen ortam materyalleri olan Bazaltik Pomza, Kokopit, Torf ve Perlit konu ile ilgili bütün kaynaklarda topraksız yetiştiricilik için önerilen ortamlar arasında yer almaktadır (Kasım ve Kasım 2004; MEGEP 2008; Daşgan ve ark. 2009; Gül 2012; Varış ve ark. 2012). Yetiştirme ortamları: 1. Bazaltik Pomza, 2. Kokopit (Hindistan cevizi torfu) ve 3. Perlit:Torf (2:1) şeklinde planlanmıştır.

Yetiştiricilik, saksı kültürüne uygun, çapı $44 \mathrm{~cm}$, yüksekliği $34 \mathrm{~cm}$ ve hacmi yaklaşık 32 litre olan toprak rengi saksılarda yapılmıştır.

\subsection{Besin Solüsyonlarl}

Çalışmada, tarafımızdan asmaya uyarlanmış değiştirilmiş Hoagland çözeltisi (A) (Tangolar ve ark. 2017) ile Buttaro ve ark. (2012)'nın kullandığı besin çözeltisi (B) kullanılmıştır. Kullanılan besin solüsyonunun içeriği Çizelge 1 'de verilmiştir.

Çizelge 1. Denemede kullanılan besin solüsyonları.

Table 1. Nutrient solutions used in the experiment.

\begin{tabular}{|c|c|c|c|c|c|}
\hline Element & Formül & $\begin{array}{l}\text { Değiştirilmiş Hoagland-A } \\
\text { (ppm) }\end{array}$ & $\begin{array}{c}\text { Verilen toplam } \\
\text { miktar mg bitki-1 }\end{array}$ & $\begin{array}{c}\text { Değiştirilmiş Hoagland- B } \\
(\mathbf{p p m})\end{array}$ & $\begin{array}{c}\text { Verilen toplam } \\
\text { miktar mg bitki }{ }^{-1}\end{array}$ \\
\hline $\mathrm{N}$ & $\mathrm{K}_{2}\left(\mathrm{NO}_{3}\right)_{2}$ & 150 & 34798 & 224 & 34046 \\
\hline $\mathrm{P}$ & $\mathrm{H}_{3} \mathrm{PO}_{4}$ & 30 & 6958 & 62 & 9424 \\
\hline $\mathrm{K}$ & $\mathrm{K}_{2} \mathrm{SO}_{4}$ & 175 & 40595 & 235 & 35720 \\
\hline $\mathrm{Mg}$ & $\mathrm{MgSO}_{4} .7 \mathrm{H}_{2} \mathrm{O}$ & 20 & 5155 & 24 & 4053 \\
\hline $\mathrm{Fe}$ & Fe-EDTA & 5 & 1289 & 1.12 & 189 \\
\hline $\mathrm{Mn}$ & $\mathrm{MnSO}_{4} \mathrm{H}_{2} \mathrm{O}$ & 3 & 696 & 0.11 & 165 \\
\hline $\mathrm{B}$ & $\mathrm{H}_{3} \mathrm{BO}_{3}$ & 0.40 & 93 & 0.27 & 42 \\
\hline $\mathrm{Cu}$ & $\mathrm{CuSO}_{4} 5 \mathrm{H}_{2} \mathrm{O}$ & 0.02 & 5 & 0.03 & 5 \\
\hline $\mathrm{Zn}$ & $\mathrm{ZnSO}_{4} 7 \mathrm{H}_{2} \mathrm{O}$ & 1 & 232 & 0.13 & 19 \\
\hline Mo & $\left(\mathrm{NH}_{4}\right)_{6} \mathrm{Mo}_{7} \mathrm{O}_{24} 4 \mathrm{H}_{2} \mathrm{O}$ & 0.05 & 12 & 0.05 & 6 \\
\hline
\end{tabular}


Çalışmada kullanılan stok besin solüsyonundan gözlerin uyanmasından başlayarak tam çiçeklenme dönemine kadar saksı başına A besin çözeltisinden $25 \mathrm{ml}$ makro, $12.5 \mathrm{ml}$ mikro; $\mathrm{B}$ besin çözeltisinden $16 \mathrm{ml}$ makro, $8 \mathrm{ml}$ mikro besin çözeltisi verilmiştir. Uygulamada, tane tutumu- ben düşme dönemi arasında A çözeltisinden $33 \mathrm{ml}$ makro, $16.5 \mathrm{ml}$ mikro, B çözeltisinden $22 \mathrm{ml}$ makro, $11 \mathrm{ml}$ mikro elementler verilmiştir.

Hasattan sonra gübre dozu, bütün uygulamalarda başlangıçta verilen miktara çekilerek eylül ayı başına kadar uygulanmıştır. EC değerleri $2-4.5 \mathrm{dS} \mathrm{m}^{-1}$ aralığında ve $\mathrm{pH}$ ise 5.5-6.0 arasında düzenlenmiştir. Kullanılan şebeke suyunun EC değeri $0.7 \mathrm{dS} \mathrm{m}^{-1}$ olarak ölçülmüştür.

Sulama, uygulanan suyun yaklaşık \%15-\%30'u drene olacak şekilde düzenlenmiştir (Kıyak 2008; Gül 2012).

Üç farklı yetiştirme ortamında büyüyen, iki yaşındaki bitkilerde bir yaşlı dallar Ocak ayında yaklaşık 1 metre uzunluktan kesilmiştir. Bu dallar, $60 \mathrm{~cm}$ yükseklikteki yatırma tellerine bağlanarak tek kollu guyot (40 cm uzunluğunda, 5-6 göz) şekli verilmiştir. Her yetiştirme ortamı için toplam 18 adet saksı kullanılmıştır. Deneme 3 tekerrürlü ve her tekerrürde 2 bitki olacak şekilde düzenlenmiş, her besin solüsyonu için toplam 6 bitki kullanılmıştır. Saksılar sera içerisine, sıra arası $150 \mathrm{~cm}$, sıra üzeri $75 \mathrm{~cm}$ olacak şekilde yerleştirilmiştir. Çalışmada kullanılan besin çözeltilerinin bileşimi ve uyanmaolgunluk arasında verilen saf element miktarları Çizelge 1'de sunulmuştur. Besin çözeltileriyle birlikte saksılara uyanmaolgunluk arası dönemde toplam 132.5 litre su verilmiştir.

Araştırmada, Gövde çapı (mm); gözlerin sürme zamanında, tam çiçeklenme, ben düşme ve olgunluk döneminde olmak üzere dört farklı fenolojik dönemde gövdenin $10 \mathrm{~cm}$ 'lik üst kısmından bir dijital kumpas yardımıyla ölçülmüştür.

Bitkilerin klorofil miktarı, bir SPAD-502 Plus klorofil metre cihazı ile olgunluk zamanında olgun yapraklarda her saksıda 3 yapraktan olmak üzere yapılmış okumalarla belirlenmiştir.

Verim ve Kalite Özelikleri kapsamında; verim $\left(\mathrm{g} \mathrm{omca}^{-1}\right)$, salkım ağırlığı $(\mathrm{g})$, yüz tane ağırlığı $(\mathrm{g})$, yüz tane hacmi $(\mathrm{ml})$, Suda Çözünebilir Kuru Madde (SÇKM) (\%), titre edilebilir asitlik $\left(\%\right.$ Asitlik $\left(\mathrm{g} 100 \mathrm{ml} \mathrm{şrar}^{-1}\right), \mathrm{pH}$, Olgunluk indisi incelenmiştir. $\mathrm{Bu}$ özellikler için ölçüm ve analizler, her tekerrürden alınan 5 salkım örneği kullanılarak yapılmıştır.

Bitki Besleme Analizleri kapsamında ben düşme döneminde alınan yaprak örneklerinde, makro ve mikro besin element analizleri yapılmıştır.
Bitki besleme analizleri için alınan yaprak örnekleri laboratuarda önce iki kez çeşme suyu altında yıkanmış ve sonra iki kez saf sudan geçirilmiştir. Islak yapraklar, kaba filtre kâğıdı ile suyu alındıktan sonra $65^{\circ} \mathrm{C}$ 'de etüvde 72 saat kurutulmuştur. Kurutulan yaprak örnekleri agat değirmende öğ̈̈tülerek analize hazır hale getirilmiştir. Ögütülen örnekler kül fırınında $450 \pm 5^{\circ} \mathrm{C}^{\prime}$ de bir gece yakılıp kuru yakma yöntemine göre $0.1 \mathrm{~N}$ $\mathrm{HNO}_{3}$ ile süzük hazırlanmıştır. Mavi bant filtre kâğıdı ile süzülen örneklerin element ölçümleri standart yöntemlere göre yapılmıştır (Kacar 1972; Aksu 2008).

Yaprak örneklerinde azot $(\mathrm{N})$, Bremner (1965) tarafindan bildirildiği şekilde Kjeldahl; toplam fosfor (P), vanadomolibdofosforik sarı renk yöntemine göre Shimadzu model UV 1201 spektrofotometresi kullanılarak saptanmıştır (Kacar 1972).

Yaprakların, toplam potasyum $(\mathrm{K})$ içerikleri Eppendorf Elex 6361 Fleymfotometresi; kalsiyum (Ca), magnezyum (Mg), demir $(\mathrm{Fe})$, çinko $(\mathrm{Zn})$, mangan $(\mathrm{Mn})$ ve bakır $(\mathrm{Cu})$ içerikleri ise Atomik Absorpsiyon spektrofotometresi yardımıla belirlenmiştir.

\subsection{Deneme Deseni ve İstatistik Analiz}

Deneme üç yinelemeli Bölünmüş Parseller deneme desenine göre planlanmıştır. Araştırmada her çeşit ayrı ayrı değerlendirilmiştir. Ana parsellere yetiştirme ortamları, alt parsellere besin çözeltisi uygulamaları yerleştirilmiştir. Parsel büyüklüğü 2 asma olarak düzenlenmiştir. Elde edilen verilere JMP istatistik programı kullanılarak varyans analizi uygulanmış ve farklı grupların saptanmasinda LSD testinden yararlanılmıştır.

\section{Bulgular ve Tartışma}

Early Sweet üzüm çeşidinde, verim ve salkım ağırlığı bakımından ortamlar ve besin çözeltileri arasında önemli farklılık bulunmuştur. En yüksek verim ve salkım ağırlı̆̆ değerleri Pomzada saptanmış (2066 g ve 344.4 g) bunu sırasıyla Perlit:Torf ve Kokopit izlemiştir. Bu özelliklerde B besin çözeltisinde değerler (1871 g, $311.8 \mathrm{~g})$, A çözeltisinden daha yüksek çıkmıştır. Tane ağırlığı ve hacmi bakımından uygulamalar arasında önemli farklılık saptanmamıştır (Çizelge 2). Early Sweet üzüm çeşidinde incelenen şıra özelliklerinde uygulamalar arasında SÇKM bakımından ve yalnızca ortamlar arasında önemli farklılık olduğu saptanmıştır. Perlit:Torf ortamında yetişen bitkilerde üzümlerin daha yüksek (\%15.30) SÇKM içeriğine sahip olduğu belirlenmiştir (Çizelge 3).

Çizelge 2. Farklı uygulamaların Early Sweet çeşidinin verim, salkım ve tane özellikleri üzerine etkisi.

Table 2. Effects of different applications on yield, cluster and berry properties of Early Sweet variety.

\begin{tabular}{|c|c|c|c|c|}
\hline Varyasyon Kaynakları & Verim $\left(\mathrm{g}_{\text {asma }}{ }^{-1}\right)$ & Salkım ağırlığı (g) & Tane ağırlı̆̆ $\left(\mathrm{g} 100 \operatorname{tane}^{-1}\right)$ & Tane hacmi (ml $\left.100 \operatorname{tane}^{-1}\right)$ \\
\hline \multicolumn{5}{|l|}{ Yetiștirme ortamı } \\
\hline Kokopit & $1321 \mathrm{c}$ & $220.1 \mathrm{c}$ & 410.8 & 381.7 \\
\hline Perit:Torf & $1889 \mathrm{~b}$ & $314.8 \mathrm{~b}$ & 409.6 & 393.3 \\
\hline Pomza & $2066 \mathrm{a}$ & $344.4 \mathrm{a}$ & 419.5 & 416.7 \\
\hline LSD $\% 5$ & 111.1 & 18.5 & Ö.D. & Ö.D. \\
\hline $\operatorname{Pr}>\mathrm{F}$ & $<0.0001$ & $<0.0001$ & 0.9269 & 0.3960 \\
\hline \multicolumn{5}{|l|}{ Besin Çözeltisi } \\
\hline A & $1646 \mathrm{~b}$ & $274.3 \mathrm{~b}$ & 429.2 & 413.3 \\
\hline B & $1871 \mathrm{a}$ & $311.8 \mathrm{a}$ & 397.4 & 381.1 \\
\hline LSD $\% 5$ & 90.7 & 15.1 & Ö.D. & Ö.D. \\
\hline $\mathrm{Pr}>\mathrm{F}$ & 0.0003 & 0.0003 & 0.1907 & 0.1452 \\
\hline \multicolumn{5}{|l|}{ İnteraksiyon } \\
\hline LSD $\% 5$ & 157.1 & 26.2 & 87.3 & 78.7 \\
\hline $\operatorname{Pr}>\mathrm{F}$ & 0.0191 & 0.0191 & 0.0506 & 0.0262 \\
\hline
\end{tabular}


Trakya İlkeren üzüm çeşidinde verim ve salkım ağırlığ değerlerinin Perlit:Torf ortamında diğer iki ortamdakinden daha yüksek (1981 g ve $495.1 \mathrm{~g}$ ) olduğu saptanmıştır. Besin çözeltisi karşıllaştırmasında ise üzüm verimi ve salkım ağırlığının B besin çözeltisi verilenlerde daha yüksek (1744 g ve $471.2 \mathrm{~g}$ ) çıktığ 1 belirlenmiştir. Tane ağırlığı ve hacmi üzerine uygulamaların etkisi istatistiksel olarak önemsiz bulunmuştur (Çizelge 4). Trakya İlkeren üzüm çeşidinde incelenen şıra özelliklerinde uygulamalar arasında şıranın pH' sı bakımından önemli farklılık saptanmamıştır. SÇKM bakımından ortamlar, asitlikte besin çözeltileri, olgunluk indisinde ise ortamlar ve besin çözeltileri arasında önemli farklılık saptanmıştır. Olgunluk indisi değerleri ise üzüm olgunlaşmasının Pomza'da diğer ortamlardan (44.68); B çözeltisinde (44.41) ise A çözeltisindekinden daha erken gerçekleştiğini göstermiştir (Çizelge 5).

Çizelge 3. Farklı uygulamaların Early Sweet çeşidinin şıra özellikleri üzerine etkisi.

Table 3. Effects of different applications on must characteristics of Early Sweet variety.

\begin{tabular}{|c|c|c|c|c|}
\hline Varyasyon Kaynakları & SÇKM (\%) & Asitlik (\%) & $\mathrm{pH}$ & Olgunluk İndisi \\
\hline \multicolumn{5}{|l|}{ Yetiştirme ortamı } \\
\hline Kokopit & $14.20 \mathrm{~b}$ & 0.429 & 4.00 & 33.56 \\
\hline Perit:Torf & $15.30 \mathrm{a}$ & 0.425 & 3.90 & 36.32 \\
\hline Pomza & $13.78 \mathrm{~b}$ & 0.401 & 3.91 & 34.76 \\
\hline LSD $\% 5$ & 1.04 & Ö.D. & Ö.D. & Ö.D. \\
\hline $\operatorname{Pr}>\mathrm{F}$ & 0.0234 & 0.4985 & 0.2122 & 0.6455 \\
\hline \multicolumn{5}{|l|}{ Besin Çözeltisi } \\
\hline A & 14.43 & 0.419 & 3.97 & 34.83 \\
\hline $\mathrm{B}$ & 14.42 & 0.418 & 3.91 & 34.93 \\
\hline LSD $\% 5$ & Ö.D. & Ö.D. & Ö.D. & Ö.D. \\
\hline $\operatorname{Pr}>F$ & 0.9774 & 0.9585 & 0.2857 & 0.9689 \\
\hline \multicolumn{5}{|l|}{ İnteraksivon } \\
\hline LSD $\% 5$ & Ö.D. & Ö.D. & Ö.D. & Ö.D. \\
\hline $\operatorname{Pr}>F$ & 0.9694 & 0.1512 & 0.5266 & 0.3266 \\
\hline
\end{tabular}

Her sütunda ortalamalar arasındaki farkl11ıklar LSD testiyle $P \leq 0.05$ 'e göre belirlenmiştir. Ö.D. Önemli değil.

Çizelge 4. Trakya İlkeren çeşidinde farklı uygulamaların verim, salkım ve tane özellikleri üzerine etkisi.

Table 4. Effects of different applications on yield, cluster and berry properties of Trakya Ilkeren variety.

\begin{tabular}{|c|c|c|c|c|}
\hline Varyasyon Kaynakları & Verim $\left(\mathrm{g}\right.$ asma $\left.^{-1}\right)$ & Salkım ağırlığı $(\mathrm{g})$ & Tane ağırlığı $\left(\mathrm{g} 100\right.$ tane $\left.^{-1}\right)$ & Tane hacmi $\left(\mathrm{ml} 100 \operatorname{tane}^{-1}\right)$ \\
\hline \multicolumn{5}{|l|}{ Yetiştirme ortamı } \\
\hline Kokopit & $1756 \mathrm{~b}$ & $439.1 \mathrm{~b}$ & 397.4 & 375.0 \\
\hline Perit:Torf & 1981 a & $495.1 \mathrm{a}$ & 429.2 & 395.8 \\
\hline Pomza & $1167 \mathrm{c}$ & $388.9 \mathrm{c}$ & 382.5 & 357.2 \\
\hline LSD $\% 5$ & 32.1 & 8.65 & Ö.D. & Ö.D. \\
\hline $\operatorname{Pr}>\mathrm{F}$ & $<0.0001$ & $<0.0001$ & 0.4033 & 0.5088 \\
\hline \multicolumn{5}{|l|}{ Besin Çözeltisi } \\
\hline A & $1525 \mathrm{~b}$ & $410.9 \mathrm{~b}$ & 395.9 & 371.4 \\
\hline $\mathrm{B}$ & $1744 \mathrm{a}$ & $471.2 \mathrm{a}$ & 410.2 & 380.6 \\
\hline LSD $\% 5$ & 26.2 & 7.06 & Ö.D. & Ö.D. \\
\hline $\operatorname{Pr}>\mathrm{F}$ & $<0.0001$ & $<0.0001$ & 0.6139 & 0.7359 \\
\hline \multicolumn{5}{|l|}{ İnteraksiyon } \\
\hline LSD $\% 5$ & 45.4 & 12.2 & Ö.D. & Ö.D. \\
\hline $\operatorname{Pr}>F$ & $<0.0001$ & $<0.0001$ & 0.3771 & 0.3456 \\
\hline
\end{tabular}

Her sütunda ortalamalar arasındaki farklılıklar LSD testiyle $P \leq 0.05$ 'e göre belirlenmiştir. Ö.D. Önemli değil.

Çizelge 5. Trakya İlkeren çeşidinde farklı uygulamaların şıra özellikleri üzerine etkisi

Table 5. Effects of different applications on must characteristics of Trakya Ilkeren variety.

\begin{tabular}{|c|c|c|c|c|}
\hline Varyasyon Kaynakları & SÇKM (\%) & Asitlik (\%) & $\mathrm{pH}$ & Olgunluk İndisi \\
\hline \multicolumn{5}{|l|}{ Yetiştirme ortamı } \\
\hline Kokopit & $15.55 \mathrm{~b}$ & 0.412 & 4.07 & $38.08 \mathrm{~b}$ \\
\hline Perit:Torf & $16.23 b$ & 0.403 & 4.07 & $40.85 \mathrm{ab}$ \\
\hline Pomza & $17.72 \mathrm{a}$ & 0.399 & 4.11 & $44.68 \mathrm{a}$ \\
\hline LSD $\% 5$ & 1.48 & Ö.D. & Ö.D. & 5.39 \\
\hline $\operatorname{Pr}>F$ & 0.0230 & 0.7224 & 0.6546 & 0.0613 \\
\hline \multicolumn{5}{|l|}{ Besin Çözeltisi } \\
\hline A & 16.52 & $0.435 \mathrm{a}$ & 4.04 & $38.00 \mathrm{~b}$ \\
\hline $\mathrm{B}$ & 16.49 & $0.374 \mathrm{~b}$ & 4.12 & $44.41 \mathrm{a}$ \\
\hline LSD $\% 5$ & Ö.D. & 0.03 & Ö.D. & 4.40 \\
\hline $\mathrm{Pr}>\mathrm{F}$ & 0.9616 & 0.0009 & 0.1011 & 0.0088 \\
\hline \multicolumn{5}{|l|}{ İnteraksiyon } \\
\hline LSD $\% 5$ & 2.09 & 0.05 & Ö.D. & 7.63 \\
\hline $\operatorname{Pr}>F$ & 0.4351 & 0.5078 & 0.8703 & 0.4065 \\
\hline
\end{tabular}

Her sütunda ortalamalar arasındaki farklılıklar LSD testiyle $P \leq 0.05$ 'e göre belirlenmiştir. Ö.D. Önemli değil. 
Early Sweet üzüm çeşidinde uygulamaların yaprakların makro ve mikro element içeriklerine etkilerine bakıldığında, $P$, $\mathrm{K}$ ve $\mathrm{Mn}$ açısından Kokopit'te; $\mathrm{Ca}$ ve $\mathrm{Mg}$ bakımından Pomza'da değerlerin daha yüksek olduğu görülmüştür (Çizelge 6). Ortamlarla ilgili olarak yapılan başlangıç analizinde Kokopit'te \%0.9 oranında K saptamış olmamız yanında Gül (2012)'de belirtilen bir miktar Mn' in bulunmasının, Kokopitte Pomza'ya göre belirtilen elementlerde değerlerin yüksek çıkmasına neden olduğu değerlendirilmiștir. Kokopit pH'sının 5.5-6.5 olmasının da bu elementlerde alım için ilave uygun ortam oluşturduğu değerlendirilmiştir. Pomza'da $\mathrm{Ca}$ ve $\mathrm{Mg}$ değerleri Sevindi (2003) ve Yaşar ve Erdoğan (2005) ile Gül (2012)'e göre sirasıyla \%11-13 ve \%6-7; Kokopitte ise analiz sonuçlarımız ve Gül (2012)'e göre Ca için \%0.11-0.40 ve $\mathrm{Mg}$ için \%0.07 düzeyinde bulunmuştur. Pomza ile Kokopit arasındaki $\mathrm{Ca}$ ve $\mathrm{Mg}$ bakımından farklılı̆̆ın ortamların bu içeriklerinden kaynaklanmış olabileceği düşünülmektedir. A çözeltisi için N ve K değerlerinin (\%3.18 ve \%1.07); B çözeltisi için $\mathrm{Ca}, \mathrm{Mg}$ ve $\mathrm{Mn}$ değerlerinin (\%1.53, \%1.09 ve $237.0 \mathrm{ppm})$ daha yüksek çıktığı belirlenmiştir (Çizelge 6). Besin çözeltilerinin bileșimlerine bakıldığında (Çizelge 1) bu farklılıkların elementlerin azlığı veya fazlalığından daha çok, elementlerin antogonistik etkilerinden kaynaklanabileceğini düşündürmüştür (Özbek 1975; Kacar ve Katkat 1998). Diğer elementlerde besin çözeltileri arasında istatistiki farklılık saptanmamıştır.

Trakya İlkeren üzüm çeşidi yaprak besin elementleri değerlerine göre, N, P, Fe ve Mn elementlerinde ortam ve besin çözeltisi uygulamaları arasında önemli farklılığı çıktığı belirlenmiştir. Bu çeşitte, ortamlar arasında istatistik farklılığın yalnızca $\mathrm{K}$, Ca ve Zn bakımından saptandığı anlaşılmaktadır. En yüksek değerler; $\mathrm{N}$ için Kokopit ve Pomza'dan (\%3.06 ve \%3.26); K, Zn, Mn ve Cu için Kokopit (sırasıyla, \%2.12, 47.2 ppm, 171 ppm, 32.4 ppm); P için Perlit:Torf (\%1.33), Ca ve Fe için Pomza'dan (\%0.74 ve 209 ppm) elde edilmiştir. Besin çözeltileri bakımından daha yüksek değerlerin; $\mathrm{N}$ ve Fe için (\%3.09 ve $204 \mathrm{ppm})$ A çözeltisinde; P ve Mn için (\%1.15 ve 168 ppm) B çözeltisinde saptandığı anlaşılmaktadır (Çizelge 7). $\mathrm{Bu}$ çeşitte de elde edilen sonuçlar arasındaki farklılığın, çeşitlerin besin maddesi alımları arasındaki farklılık yanında (Kacar 1997; Çelik ve ark. 1998; Kacar ve Katkat 1998) yetiştirme ortamı pH s1, su tutma kapasitesi, porozite ve element içeriği farklılı̆̆ından (Kasım ve Kasım 2004; Yaşar ve Erdoğan 2005; Gül 2012) kaynaklandığ1 düşünülmektedir.

Çizelge 6. Farklı uygulamaların, Early Sweet çeşidinden ben düşme döneminde alınan yaprak örneklerinde makro ve mikro element içerikleri üzerine etkisi.

Table 6. Effects of different applications on macro and micro element contents in the leaf samples taken from Early Sweet variety in veraison period.

\begin{tabular}{|c|c|c|c|c|c|c|c|c|c|}
\hline \multirow[t]{2}{*}{ Varyasyon Kaynakları } & \multicolumn{5}{|c|}{ Makro elementler (\%) } & \multicolumn{4}{|c|}{ Mikro elementler (ppm) } \\
\hline & $\mathrm{N}$ & $\mathrm{P}$ & $\mathrm{K}$ & $\mathrm{Ca}$ & $\mathrm{Mg}$ & $\mathrm{Fe}$ & $\mathrm{Zn}$ & $\mathrm{Mn}$ & $\mathrm{Cu}$ \\
\hline \multicolumn{10}{|l|}{ Yetiştirme ortamı } \\
\hline Kokopit & 2.96 & $1.05 \mathrm{a}$ & $1.18 \mathrm{a}$ & $0.65 \mathrm{c}$ & $0.78 \mathrm{~b}$ & 198.5 & 37.1 & $243.0 \mathrm{a}$ & 29.2 \\
\hline Perit:Torf & 2.81 & $0.97 \mathrm{~b}$ & $0.58 \mathrm{~b}$ & $1.11 \mathrm{~b}$ & $0.92 \mathrm{~b}$ & 205.0 & 36.3 & $172.0 \mathrm{~b}$ & 36.2 \\
\hline Pomza & 2.97 & $0.35 \mathrm{~b}$ & $0.66 \mathrm{~b}$ & $2.10 \mathrm{a}$ & $1.06 \mathrm{a}$ & 217.5 & 38.4 & $161.0 \mathrm{~b}$ & 32.3 \\
\hline LSD \%5 & Ö.D. & 0.15 & 0.25 & 0.20 & 0.14 & Ö.D. & Ö.D. & 67.7 & Ö.D. \\
\hline $\operatorname{Pr}>\mathrm{F}$ & 0.5557 & $<0.0001$ & 0.0006 & $<0.0001$ & 0.0037 & 0.2349 & 0.8459 & 0.0454 & 0.3632 \\
\hline \multicolumn{10}{|l|}{ Besin Çözeltisi } \\
\hline A & $3.18 \mathrm{a}$ & 0.76 & $1.07 \mathrm{a}$ & $1.04 \mathrm{~b}$ & $0.74 \mathrm{~b}$ & 210.0 & 40.0 & $147.0 \mathrm{~b}$ & 31.9 \\
\hline $\mathrm{B}$ & $2.63 \mathrm{~b}$ & 0.82 & $0.54 \mathrm{~b}$ & $1.53 \mathrm{a}$ & $1.09 \mathrm{a}$ & 204.0 & 34.5 & $237.0 \mathrm{a}$ & 33.2 \\
\hline LSD $\% 5$ & 0.29 & Ö.D. & 0.20 & 0.16 & 0.11 & Ö.D. & Ö.D. & 67.7 & Ö.D. \\
\hline $\operatorname{Pr}>\mathrm{F}$ & 0.0017 & 0.2414 & 0.0002 & $<0.0001$ & $<0.0001$ & 0.4969 & 0.0782 & 0.0045 & 0.7415 \\
\hline \multicolumn{10}{|l|}{ İnteraksiyon } \\
\hline LSD $\% 5$ & Ö.D. & 0.21 & 0.35 & 0.28 & Ö.D. & Ö.D. & Ö.D. & Ö.D. & Ö.D. \\
\hline $\operatorname{Pr}>\mathrm{F}$ & 0.9034 & 0.0044 & 0.0043 & 0.0559 & 0.5431 & 0.6403 & 0.4114 & 0.2999 & 0.7935 \\
\hline
\end{tabular}

Her sütunda ortalamalar arasındaki farklılıklar LSD testiyle $P \leq 0.05$ 'e göre belirlenmiştir. Ö.D. Önemli değil.

Çizelge 7. Farklı uygulamaların, Trakya İlkeren çeşidinden ben düşme döneminde alınan yaprak örneklerinde makro ve mikro element içerikleri üzerine etkisi.

Table 7. Effects of different applications on macro and micro element contents in the leaf samples taken from Trakya Ilkeren variety in veraison period.

\begin{tabular}{|c|c|c|c|c|c|c|c|c|c|}
\hline \multirow[t]{2}{*}{ Varyasyon Kaynakları } & \multicolumn{5}{|c|}{ Makro elementler (\%) } & \multicolumn{2}{|c|}{ Mikro elementler (ppm) } & \multirow[b]{2}{*}{$\mathrm{Mn}$} & \multirow[b]{2}{*}{$\mathrm{Cu}$} \\
\hline & $\mathrm{N}$ & $\mathrm{P}$ & $\mathrm{K}$ & $\mathrm{Ca}$ & $\mathrm{Mg}$ & $\mathrm{Fe}$ & $\mathrm{Zn}$ & & \\
\hline \multicolumn{10}{|l|}{ Yetiștirme ortamı } \\
\hline Kokopit & $3.06 \mathrm{a}$ & $1.10 \mathrm{~b}$ & $2.12 \mathrm{a}$ & $0.32 \mathrm{~b}$ & 0.41 & $181 \mathrm{~b}$ & $47.2 \mathrm{a}$ & $171 \mathrm{a}$ & $32.4 \mathrm{a}$ \\
\hline Perit:Torf & $2.62 \mathrm{~b}$ & $1.33 \mathrm{a}$ & $1.26 \mathrm{~b}$ & $0.47 \mathrm{~b}$ & 0.47 & $186 \mathrm{ab}$ & $36.7 \mathrm{~b}$ & $127 \mathrm{~b}$ & $25.6 \mathrm{ab}$ \\
\hline Pomza & $3.26 \mathrm{a}$ & $0.46 \mathrm{c}$ & $0.99 \mathrm{~b}$ & $0.74 \mathrm{a}$ & 0.48 & $209 a$ & $35.9 \mathrm{~b}$ & $138 \mathrm{~b}$ & $20.6 \mathrm{~b}$ \\
\hline LSD $\% 5$ & 0.22 & 0.12 & 0.48 & 0.21 & Ö.D. & 26.1 & 6.3 & 21.1 & 9.0 \\
\hline $\operatorname{Pr}>\mathrm{F}$ & 0.0002 & $<0.0001$ & 0.0009 & 0.0042 & 0.1151 & 0.0821 & 0.0041 & 0.0025 & 0.0438 \\
\hline \multicolumn{10}{|l|}{ Besin Çözeltisi } \\
\hline A & $3.09 \mathrm{a}$ & $0.78 \mathrm{~b}$ & 1.56 & 0.44 & 0.42 & $204 \mathrm{a}$ & 40.2 & $122 \mathrm{~b}$ & 23.8 \\
\hline $\mathrm{B}$ & $2.87 \mathrm{~b}$ & $1.15 \mathrm{a}$ & 1.35 & 0.58 & 0.47 & $180 \mathrm{~b}$ & 39.6 & $168 \mathrm{a}$ & 28.6 \\
\hline LSD $\% 5$ & 0.18 & 0.10 & Ö.D. & Ö.D. & Ö.D. & 21.3 & Ö.D. & 17.2 & Ö.D. \\
\hline $\operatorname{Pr}>\mathrm{F}$ & 0.0206 & $<0.0001$ & 0.2677 & 0.0942 & 0.0970 & 0.0318 & 0.7741 & 0.0002 & 0.1810 \\
\hline \multicolumn{10}{|l|}{ İnteraksiyon } \\
\hline LSD $\% 5$ & 0.31 & 0.17 & Ö.D. & Ö.D. & Ö.D. & Ö.D. & Ö.D. & 29.8 & Ö.D. \\
\hline $\mathrm{Pr}>\mathrm{F}$ & 0.0215 & 0.0078 & 0.6060 & 0.0918 & 0.1410 & 0.2947 & 0.3138 & 0.0001 & 0.2323 \\
\hline
\end{tabular}

Her sütunda ortalamalar arasındaki farklılıklar LSD testiyle $P \leq 0.05$ 'e göre belirlenmiștir. Ö.D. Önemli değil. 
Early Sweet ve Trakya İlkeren çeşitlerinde farklı fenolojik zamanlarda ölçülen gövde çapları üzerine farklı ortam ve besin çözeltisi uygulamasının önemli bir etkisinin olmadığ belirlenmiştir (Çizelge 8 ve 9). Early Sweet ve Trakya İlkeren çeşidinde olgunluk zamanında ölçülen SPAD değerleri bakımından yetiştirme ortamları arasındaki farklılığın önemli; besin çözeltileri arasındaki farklılığın ise önemsiz olduğu saptanmıştır. Early Sweet çeşidinde en yüksek SPAD değerleri aynı istatistiksel grupta yer alan Pomza (47.37) ve Perlit:Torf (46.32) ortamlarında; Trakya İlkeren çeşidinde ise Pomza (43.62) ortamındaki bitkilerde belirlenmiştir (Çizelge 8 ve 9).

\section{Sonuç}

Üzüm verimi ve salkım ağırlığı bakımından Early Sweet'te Pomza, Trakya İlkeren çeşidinde ise Perlit:Torf ortamımın; çözeltiler arsında ise her iki çeşit için B çözeltisinin daha etkili olduğu değerlendirilmiştir.

Yaprak besin maddesi içerikleri çeşitlerde ortamlar ve kullanılan besin çözeltilerine göre farklılık göstermiştir. Genel olarak Kokopit ve Pomza ortamlarında değerlerin daha yüksek olduğu belirtilebilir.

Çizelge 8. Early Sweet çeşidinde farklı fenolojik dönemlerde ölçülen çap değerleri (mm).

Table 8. Stem diameter $(\mathrm{mm})$ values measured in different phenological periods of Early Sweet variety.

\begin{tabular}{|c|c|c|c|c|c|}
\hline Varyasyon Kaynakları & Sürme & Tam çiçeklenme & Ben düşme & Olgunluk & SPAD (Olgunlukta) \\
\hline \multicolumn{6}{|l|}{ Yetiştirme ortamı } \\
\hline Kokopit & 14.78 & 16.48 & 16.65 & 16.31 & $42.12 \mathrm{~b}$ \\
\hline Perit:Torf & 14.88 & 16.32 & 16.68 & 16.48 & $46.32 \mathrm{a}$ \\
\hline Pomza & 15.11 & 15.83 & 16.32 & 16.05 & $47.37 \mathrm{a}$ \\
\hline LSD $\% 5$ & Ö.D. & Ö.D. & Ö.D. & Ö.D. & 2.78 \\
\hline $\operatorname{Pr}>\mathrm{F}$ & 0.9347 & 0.7674 & 0.9433 & 0.9110 & 0.0042 \\
\hline \multicolumn{6}{|l|}{ Besin Çözeltisi } \\
\hline A & 14.79 & 16.38 & 17.02 & 16.75 & 44.15 \\
\hline B & 15.05 & 16.03 & 16.07 & 15.80 & 46.77 \\
\hline LSD $\% 5$ & Ö.D. & Ö.D. & Ö.D. & Ö.D. & Ö.D. \\
\hline $\operatorname{Pr}>\mathrm{F}$ & 0.7335 & 0.6504 & 0.3422 & 0.2707 & 0.0539 \\
\hline \multicolumn{6}{|l|}{ İnteraksiyon } \\
\hline $\operatorname{LSD} \% 5$ & Ö.D. & Ö.D. & Ö.D. & Ö.D. & 3.93 \\
\hline $\operatorname{Pr}>\mathrm{F}$ & 0.5471 & 0.2837 & 0.5474 & 0.6802 & 0.6301 \\
\hline
\end{tabular}

Her sütunda ortalamalar arasındaki farklılıklar LSD testiyle $P \leq 0.05$ 'e göre belirlenmiştir. Ö.D. Önemli değil.

Çizelge 9. Trakya İlkeren çeşidinde farklı fenolojik dönemlerde ölçülen çap değerleri (mm).

Table 9. Stem diameter $(\mathrm{mm})$ values measured in different phenological periods of Trakya Ilkeren variety.

\begin{tabular}{|c|c|c|c|c|c|}
\hline Varyasyon Kaynakları & Sürme & Tam çiçeklenme & Ben düşme & Olgunluk & SPAD (Olgunlukta) \\
\hline \multicolumn{6}{|l|}{ Yetiştirme ortamı } \\
\hline Kokopit & 15.35 & 16.60 & 16.49 & 16.96 & $40.00 \mathrm{~b}$ \\
\hline Perit:Torf & 14.83 & 16.42 & 16.45 & 16.62 & $42.33 \mathrm{ab}$ \\
\hline Pomza & 14.30 & 15.56 & 16.04 & 16.01 & $43.62 \mathrm{a}$ \\
\hline LSD $\% 5$ & Ö.D. & Ö.D. & Ö.D. & Ö.D. & 3.47 \\
\hline $\operatorname{Pr}>F$ & 0.2591 & 0.1530 & 0.5349 & 0.3413 & 0.1105 \\
\hline \multicolumn{6}{|l|}{ Besin Çözeltisi } \\
\hline A & 14.94 & 16.44 & 16.46 & 16.68 & 41.70 \\
\hline $\mathrm{B}$ & 14.70 & 15.94 & 16.19 & 16.37 & 42.27 \\
\hline LSD $\% 5$ & Ö.D. & Ö.D. & Ö.D. & Ö.D. & Ö.D. \\
\hline $\operatorname{Pr}>\mathrm{F}$ & 0.6322 & 0.2625 & 0.4518 & 0.5527 & 0.6656 \\
\hline \multicolumn{6}{|l|}{ İnteraksiyon } \\
\hline LSD $\% 5$ & Ö.D. & Ö.D. & Ö.D. & Ö.D. & 4.91 \\
\hline $\operatorname{Pr}>F$ & 0.7863 & 0.7559 & 0.2512 & 0.5131 & 0.6180 \\
\hline
\end{tabular}

Her sütunda ortalamalar arasındaki farkl1lıklar LSD testiyle $P \leq 0.05$ 'e göre belirlenmiştir. Ö.D. Önemli değil.

\section{Teşekkürr}

$\mathrm{Bu}$ çalışma Çukurova Üniversitesi Bilimsel Araştırma Projeleri Koordinasyon Birimi tarafından desteklenmiştir (Proje No: FBA-2018-11073).

\section{Kaynaklar}

Aksu A (2008) Ege Bölgesinde yaygın bağcılık yapılan alanlarda tuzluluk, bor toksitesi problemlerinin ve beslenme durumunun belirlenmesi. Yüksek Lisans Tezi, Ankara Üniversitesi Fen Bilimleri Enstitüsü, Toprak Anabilim Dalı, Ankara.

Baştaş PC, Tangolar S (2018) Topraksız kültürde yetiştirilen Prima üzüm çeşidinin verim ve kalite özelliklerine farklı yetiştirme ortamı ve ürün yüklerinin etkisi. Alatarım 17(2): 98-109.

Bremner JM (1965) Total Nitrogen. In: C. A. Black (ed.) Methods of soil analysis. Part 2: Chemical and microbial properties. Number 9 in series Agronomy. American Society of Agronomy, Inc. Publisher, Madison, USA. pp. 1049-1178.

Buttaro D, Serio F, Santamaria P (2012) Soilless greenhouse production of table grape under Mediterranean conditions. Journal of Food Agriculture \& Environment 10(2): 641-645.

Çelik H, Ağaoğlu YS, Fidan Y, Marasalı B, Söylemezoğlu G (1998) Genel Bağcılık. Sunfidan A.Ş., Mesleki Kitaplar Serisi 1, s. 253.

Daşgan HY, Kuşvuran Ş, Kirda C (2009) Sera Topraksız Hiyar Yetiştiriciliğinde Kısmi Kök Bölgesi Kuruluğunun Etkileri. TÜBİTAK-TOVAG. Proje No: 105O566. s. 105.

Di Lorenzo R, Mafrica R (2000) La coltivazione fuori suolo dell'uva da tavola - Risultati di un biennio di esperienze condotte in Sicilia. Riv. Frutticolt. Orticolt 62: 48-52.

Di Lorenzo R, Gambino C, Dimauro B (2009) La coltivazione dell'uva da tavola in fuori suolo: Stato Attuale E Prospettive. Bull. OIV 82: 935-7. 
Di Lorenzo R, Dimauro B, Guarasci F, Rinoldo C, Gambino, C (2012) Multiple productive cycles in the same year in soilless table grape cultivation. P 20, in Proc. 35th Word Congr. Vine and Wine Izmir, Turkey.

Di Lorenzo R, Gambino C, Dimauro B (2005) Soilless cultivation in the table grape cultivation. Convegno Nazionale "Strategie Per İl Miglioramento Dell'orticoltura Protetta in Sicilia”. Scoglitti (RG). 25-26 Novembre. 53-64.

Gül A (2012) Topraksız Tarım. Hasad Yayıncılık. İstanbul.

Hoagland DR, Arnon DI (1950) The water-culture method for growing plants without soil. California Agricultural Experiment Station Circular 347: 1-32.

Kacar B (1972) Bitki ve Toprağın Kimyasal Analizleri. II. Bitki Analizleri. Ankara Üniv. Ziraat Fak. Yayınları 453, Uygulama Kılavuzu 155, Ankara Üniv. Basımevi, Ankara.

Kacar B (1997) Gübre Bilgisi. Ankara Üniv. Ziraat Fak. Yayınları No: 1490, Ders Kitab1, 449. s. 441.

Kacar B, Katkat AV (1998) Bitki Besleme. Uludağ Üniv. Güçlendirme Vakfı Yayın No: 127, VİPAŞ Yayınları: 3, s. 595.

Kasım R, Kasım U (2004) Topraksız yetiştiricilik. Kocaeli Üniv. Yayınları. No: 130.

Kaya S, Tangolar S, Tangolar S (2018) Farklı Katı Kültür Ortamlarında Yetiştirilen Farklı Yaşlardaki Bazı Sofralık Üzüm Çeşitlerinde Kök Budama Uygulamasının Verim ve Kaliteye Etkisi. BAHÇE 47 (Özel Sayı 1: Türkiye 9. Bağcılık ve Teknolojileri Sempozyumu): 575-585.

Kıyak A (2008) Tam Otomasyonlu Polikarbon Serada Topraksız Kültürde Yetiştirilen Hiyarın (Cucumis Sativus L.) Sulama Programının Belirlenmesi. Yüksek Lisans Tezi. Harran Üniversitesi. Fen Bilimleri Enstitüsü. Tarımsal Yapılar ve Sulama Anabilim Dalı.

MEGEP (2008) MEGEP (Mesleki Eğitim Ve Öğretim Sisteminin Güçlendirilmesi Projesi). Bahçecilik. Topraksız Tarıma Hazırlık. http://hbogm.meb.gov.tr/modulerprogramlar/kursprogramlari/bahce cilik/moduller/topraksiz_tarima_hazirlik. pdf. Erişim 30 Ağustos 2018.
Özbek N (1975) Bağ-Bahçe Bitkilerinin Gübrelenmesi. I. Bağların Gübrelenmesi. A. Ü. Ziraat Fak. Yayınlar1:576. Ders Kitabı: 193.

Polat İ, Özkan CF, Kaya H, Eski H (2003) Topraksız Kültür Üzüm Yetiştiriciliğinde Farklı Ortamların Erkencilik. Kalite ve Verime Etkisi. Türkiye 4. Ulusal Bahçe Bitkileri Kongresi, Antalya, s. 493496.

Sabır A, Karaca U, Yazar K, Sabir FK, Yazici MA, Dogan O, Kara Z (2017) Vine growth and yield response of Alphonse Lavallée ( $V$. Vinifera L.) grapevines to plant growth promotıng rhizobacteria under alkaline condition in soilless culture. Acta Scientiarum Polonorum-Hortorum Cultus 16(4): 25-32.

Sabır A, Sabir F, Yazar K, Kara Z (2012) Investigation on development of some grapevine cultivars (V. vinifera $L$.) in soilless culture under controlled glasshouse condition. Current Trends in Technonlogy and Science 5(3): 622-626.

Sevindi C (2003) Kars İli Perlit yataklarının ekonomik önemi ve değerlendirilmesi. Kars Sosyal Bilimler Dergisi 3(30): 169-186.

Tangolar S, Tangolar S, Alkan Torun A, Tarım G, Ada M, Ertargın E (2016) The effects of different nitrogen and potassium levels on yield and quality of two early grape cultivars grown in different soilless media. III International Symposium on Horticulture in Europe. 17-21 October 2016. Crete. Greece.

Tangolar S, Tangolar S, Alkan Torun A, Tarım G, Ada M (2017) Topraksız kültür sisteminde sofralık üzüm yetiştiriciliğinin araştırılması. Türkiye Tarımsal Araştırmalar Dergisi 4(2): 163-170.

Varış S, Altıntaş S, Küçükçelik B (2012) Topraksız kültür yöntemleri. Besin çözeltisinde $\mathrm{pH}$, EC kontrolü ve element seviyelerine göre gereken gübre miktarlarının hesaplanması. Tarlasera. 17 ve 18: 72$77 \mathrm{~s}$ ve $58-60$.

Yaşar E, Erdoğan Y (2005) Asidik (Nevşehir) ve Bazik (Osmaniye) Pomzaların yapı sektöründe değerlendirilmesi. Türkiye 19. Uluslar Arası Madencilik Kongresi ve Fuarı, Izmir. 